\title{
Prevalence and duration of symptoms among moderate and severe COVID-19 patients 12 months after discharge
}

\author{
C. Tortajada ${ }^{1}$ (1) - A. Navarro² $\cdot$ J. C. Andreu-Ballester ${ }^{3} \cdot$ A. Mayor $^{2} \cdot$ S. Añón ${ }^{2} \cdot$ J. Flores $^{1}$
}

Received: 19 May 2021 / Accepted: 15 November 2021 / Published online: 13 January 2022

(c) Società Italiana di Medicina Interna (SIMI) 2021

Keywords Post-COVID-19 · Long-term symptoms · COVID-19 · Cohort study · Health-related quality of life

Dear Editor,

Studies on the severe acute respiratory syndrome coronavirus (SARS-CoV) and the Middle East respiratory syndrome coronavirus (MERS-CoV) have shown that coronavirus infection survivors suffered afterwards from chronic health complications [1,2] Recently, 2-6 months follow-up studies on series of patients after COVID-19 infection have reported several health problems such as fatigue, dyspnoea, and musculoskeletal or neuropsychological symptoms [3-8]. However, more than 1 year after the first cases, there is still little information on COVID-19-related symptoms in the long term.

The aim of the present study was, among hospitalized patients with mild to severe COVID-19, to evaluate the persistence of symptoms, their duration, and their impact on daily life 1 year after the acute infection. We also aimed to assess possible predictor factors associated with the persistence of symptoms.

C. Tortajada

ctortaja@gmail.com

1 Infectious Disease Unit, Internal Medicine Department, Hospital Arnau de Vilanova, San Clemente 12, 46015 Valencia, Spain

2 Internal Medicine Department, Hospital Arnau de Vilanova, San Clemente 12, 46015 Valencia, Spain

3 Research Department, Hospital Arnau de Vilanova, San Clemente 12, 46015 Valencia, Spain
The present work is a follow-up study of patients who participated in our previous cohort study [9] conducted at the Arnau de Vilanova-Llíria Health Department in Valencia, Spain. This health centre is part of the National Health System and covers an area of 311,000 inhabitants. We reviewed all patients who were consecutively admitted to hospital diagnosed with suspected COVID-19 during the first wave, between March 3, and April 30, 2020. The inclusion criteria were patients aged $\geq 18$ years, with oxygen saturation while breathing room air $\left(\mathrm{SatO}_{2}\right)<92 \%$, and who had laboratory confirmation of COVID-19 infection by RT-PCR in a nasopharyngeal swab. Patients were excluded in case of in-hospital death or if telephone contact was inappropriate because of dementia, mental disorders, or any other cognitive or communication impairment.

Members of the COVID-19 team called patients 12 months after discharge and use a self-designed questionnaire during the phone interviews. The patients were asked about the symptoms considered more prevalent in the post-acute COVID-19 syndrome, according to the published series reviewed $[3,4]$. The team also used validated questionnaires for the assessment of anxiety or depression (Goldberg scale [10]), dyspnoea (mMRC modified British Medical Research Council [11]) and quality of life (EQ-5D-5L [12]). Patients self-reported the duration of symptoms. Persistent symptoms are defined as those which were present since the beginning of the infection and lasted for more than 4 weeks.

Demographic and clinical data were recorded from patients' electronic medical records.

Patients gave informed verbal consent to proceed during the telephone interview. The study was conducted according to the Declaration of Helsinki, and it was approved by the Arnau de Vilanova-Llíria Hospitals' Ethics Committee.

The primary end point was symptoms' evaluation (frequency and duration) and assessment of quality of life 1 year 
after the acute infection. The secondary end point was the identification of risk factors for persistent symptoms.

The categorical variables were presented as percentage, and continuous variables as mean and $95 \%$ confidence interval (CI). For comparison between groups with and without symptoms, the Chi-square and the $t$ test were used. Multivariable logistic regressions were performed to evaluate associations between selected variables and the presence of symptoms. Variables were included if they showed significant association in the univariate analysis or were considered of clinical interest by the authors. Odds ratio (OR) with $95 \%$ CI were estimated. $p$ values were two sided and value $<0.05$ was considered statistically significant. Statistical analysis was performed using the Statistical Package for Social Science (SPSS 19.0 Inc, Chicago, IL).

Out of 287 hospitalized patients evaluated in the first pandemic wave, our cohort study included 115 who met the inclusion criteria (patients aged $\geq 18$ years, with oxygen saturation while breathing room air $\left.\left(\mathrm{SatO}_{2}\right)<92 \%\right)$ [9]. From those, 24 patients died while in hospital and 16 discharged patients were unable to respond the questionnaire due to cognitive disorders. The remaining 75 patients were included in the telephone follow-up. Among those, 4 of them had died after discharge and 3 did not answer their phones. Finally, 68 patients were included in the analysis. The mean follow-up time was 46 weeks.

The mean (95\% CI) age of patients was 64 (61-68) years and $72 \%$ were men. Forty-five $(66 \%)$ required oxygen therapy and 23 (34\%) required high flow oxygen (HFO) or mechanical ventilation (MV), either non-invasive (NIV) or invasive (IMV). Supplementary Table 1 shows the demographic data and baseline characteristics of patients. Fatigue ( $n=40,59 \%)$, concentration problems $(n=34,51 \%)$, dyspnoea $(n=35,52 \%)$, anxiety $(n=31,46 \%)$, depression $(n=29,43 \%)$ and muscle or join ache $(n=27,40 \%)$ were the most frequent reported symptoms (Table 1). Ninety per cent of patients reported at least one persistent symptom (lasting for more than 4 weeks), and $71 \%$ reported 3 or more symptoms. After an average of 46 weeks after discharge, 23 patients $(34 \%)$ have not recovered their previous quality of life. These patients completed the EQ-5D-5L questionnaire, in which problems performing the usual activities (20 out of 23) were the most common limiting factor. Items were categorized more frequently as slight or moderate, and with lower frequency as severe. After nearly 1 year, 52 patients (76\%) continued reporting at least one symptom.

Among the most prevalent symptoms, arthromyalgia and those of the neuropsychological field (anxiety, depression, concentration problems...) lasted longer than fatigue or dyspnoea (Fig. 1). Forty-eight per cent of patients with fatigue and $42 \%$ of those with dyspnoea had their symptoms resolved after an average period of 10 weeks. However, most patients with neuropsychological symptoms or arthromyalgia reported persistent symptoms by the date of the interview.

Fatigue $(p=0.03)$ and dyspnoea $(p=0.03)$ were more frequent among women (see Supplementary Table 2), arthromyalgia was associated with younger patients $(p=0.02)$, and dyspnoea was more frequent among patients who needed HFO or MV $(p=0.05)$. Results after multivariate adjustment are shown in Table 2. A logistic regression model was built including $\mathrm{C}$-reactive protein and the use of immunomodulatory drugs (corticosteroids, interferon beta or tocilizumab), since they were considered of clinical interest by the authors. However, this analysis did not find any statistically significant association between the presence of symptoms and those variables. Consequently, they were not included in the final logistic regression model.

The results of our study showed that, 1 year after discharge, one-thirds of patients with moderate to severe COVID-19 had not recovered their previous quality of life. Moreover, nearly two-third still reported the persistence of at least one symptom, particularly fatigue, anxiety or depression, concentration problems, dyspnoea and muscle or join ache. Patients categorized these symptoms mostly as mild or moderate. A number of studies have also reported these symptoms as the most prevalent ones [3, 4, 6, 7, 13]. Moreover, the prevalence of symptoms in our cohort was also comparable with other cohorts of hospitalized patients [3, 4]. In general, prevalence of symptoms seems to be lower among patients with mild COVID-19 or outpatients [14]. We observed than neuropsychological symptoms tended to persist longer that others such as fatigue or dyspnoea. Previous systematic review and meta-analysis of the outcomes after SARS-CoV and MERS-CoV found that survivors reported symptoms which could persist up to 12-18 months [1-3]. Regarding COVID-19, a recent study showed that a considerable portion of patients still reported symptoms and disruption of their routine life 8 months after mild disease [14].

In general, symptoms reported in our study were more frequent among female and younger patients. There was a statistically significant association between being a woman and the persistent of fatigue or dyspnoea. In agreement with our results, a study that evaluated 100 patients at 48 days post discharge found that fatigue, breathlessness, and neuropsychological disorders were reported more frequently by female patients [6]. Also, a 6-month follow-up after discharge cohort study [4] found that women had an increased risk for anxiety or depression and fatigue. Similarly, another study [15] showed that fatigue, post-activity polypnea, and alopecia were more common in women. We also observed that younger patients presented more risk of arthromyalgia and concentration problems. This association with younger age has been reported also for other symptoms like anosmia-dysgeusia [7]. It is known that the disease severity in 
Table 1 Symptoms and healthrelated quality of life
Total

$(n=68)$

\begin{tabular}{|c|c|}
\hline Fatigue & $40(59 \%)$ \\
\hline \multicolumn{2}{|l|}{ Anxiety $^{\mathrm{a}}$} \\
\hline No & $36(53 \%)$ \\
\hline Mild & $8(12 \%)$ \\
\hline Moderate & $16(24 \%)$ \\
\hline Severe & $7(10 \%)$ \\
\hline Extremely & 0 \\
\hline \multicolumn{2}{|l|}{ Depression $^{\mathrm{a}}$} \\
\hline No & $38(56 \%)$ \\
\hline Mild & $12(18 \%)$ \\
\hline Moderate & $15(22 \%)$ \\
\hline Severe & $2(3 \%)$ \\
\hline Extremely & 0 \\
\hline Concentration problem & $34(51 \%)$ \\
\hline \multicolumn{2}{|l|}{ Dyspnoea mMRC ${ }^{b}$} \\
\hline Grade 0 & $33(48 \%)$ \\
\hline Grade 1 & $15(22 \%)$ \\
\hline Grade 2 & $12(18 \%)$ \\
\hline Grade 3 & $5(7 \%)$ \\
\hline Grade 4 & $3(4 \%)$ \\
\hline Muscle or join ache & $27(40 \%)$ \\
\hline Sleep difficulties & $25(37 \%)$ \\
\hline Smell/taste disorders & $22(32 \%)$ \\
\hline Headache & $18(26 \%)$ \\
\hline Dry eyes or mouth & $18(26 \%)$ \\
\hline Hair loss & $17(25 \%)$ \\
\hline Chest pain & $10(15 \%)$ \\
\hline Cough & $10(15 \%)$ \\
\hline Diarrhoea & $8(12 \%)$ \\
\hline Palpitations & $6(9 \%)$ \\
\hline Dizziness & $6(9 \%)$ \\
\hline Sore throat & $4(6 \%)$ \\
\hline Fever/low grade fever & 0 \\
\hline \multicolumn{2}{|l|}{ Persistent symptoms } \\
\hline None & $7(10 \%)$ \\
\hline 1 or 2 & $13(19 \%)$ \\
\hline 3 or more & $48(71 \%)$ \\
\hline Patients who had not recovered their previous quality of life & $23(34 \%)$ \\
\hline \multicolumn{2}{|l|}{$\begin{array}{l}{ }^{c} \text { EQ-5D-5L questionnaire } \\
(n=23)\end{array}$} \\
\hline \multicolumn{2}{|l|}{ Mobility: problems in walking about } \\
\hline No problems & $11 / 23(48 \%)$ \\
\hline Slight problems & $8 / 23(34 \%)$ \\
\hline Moderate problems & $3 / 23(13 \%)$ \\
\hline Severe problems & $1 / 23(4 \%)$ \\
\hline Unable & 0 \\
\hline \multicolumn{2}{|l|}{ Self-care: problems washing or dressing myself } \\
\hline No problems & $21 / 23(91 \%)$ \\
\hline Slight problems & $2 / 23(9 \%)$ \\
\hline Moderate problems & 0 \\
\hline
\end{tabular}


Table 1 (continued)

\begin{tabular}{ll}
\hline & $\begin{array}{l}\text { Total } \\
(n=68)\end{array}$ \\
\hline Severe problems & 0 \\
Unable & 0 \\
Usual activities & \\
No problems & $3 / 23(13 \%)$ \\
Slight problems & $10 / 23(43 \%)$ \\
Moderate problems & $8 / 23(35 \%)$ \\
Severe problems & $1 / 23(4 \%)$ \\
Unable & $1 / 23(4 \%)$ \\
Pain or discomfort & \\
No pain & $10 / 23(43 \%)$ \\
Slight pain & $5 / 23(22 \%)$ \\
Moderate pain & $6 / 23(26 \%)$ \\
Severe pain & $2 / 23(9 \%)$ \\
Extreme pain & 0 \\
Anxiety/depression & \\
Not anxious or depressed & \\
Slightly anxious or depressed & $4 / 23(17 \%)$ \\
Moderately anxious or depressed & $5 / 23(22 \%)$ \\
Severely anxious or depressed & $9 / 23(39 \%)$ \\
Extremely anxious or depressed & $5 / 23(22 \%)$ \\
Patients with at least one persistent symptom 1 year after infection & 0 \\
\hline & $52(76 \%)$ \\
\hline
\end{tabular}

Data are expressed as $n(\%)$

${ }^{a}$ Anxiety and depression were assessed using the Goldberg scale

${ }^{b}$ Dyspnoea was categorized using the mMRC (modified British Medical Research Council)

${ }^{c}$ Quality of life was assessed by the EQ-5D-5L(EuroQol five-dimensions five-level questionnaire). The scale was performed on patients who reported not recovery of his previous quality of life $(n=23)$

the acute phase is associated with pulmonary diffusion and CT pattern abnormalities and increase risk of dyspnoea [4]. Along the same line, our study showed an increased risk of dyspnoea among more severe COVID-19 patients who had required HFO or MV. As in other studies [4], we could not find an association between the use of immunomodulators or the inflammatory activity during the acute disease and the presence of persistent symptoms.

Limitations of our study include the possibility of recall bias as result of the retrospective data collection. Moreover, our study only included patients with moderate to severe disease, and the multivariable logistic regression results may be limited by the small sample size. Finally, the telephone contact was done as a single point of follow-up, so there was not information about how symptoms' severity evolved over time.

In summary, this cohort study with moderate to severe COVID-19 patients indicated that, nearly 1 year after acute infection, one-third of patients have not recovered their previous quality of life, and two-third still referred at least one symptom. The neuropsychological symptoms lasted longer than fatigue or dyspnoea. This information on symptoms and their duration might help us to better understand the long-term complication of COVID-19. It will also provide a more comprehensive information to our patients, which 
Fig. 1 Duration of symptoms. Bars represent the percentage of patients with unresolved and resolved symptoms by interview date. Dots indicate the mean duration of the resolved symptoms. Figure shows symptoms with a prevalence $>25 \%$

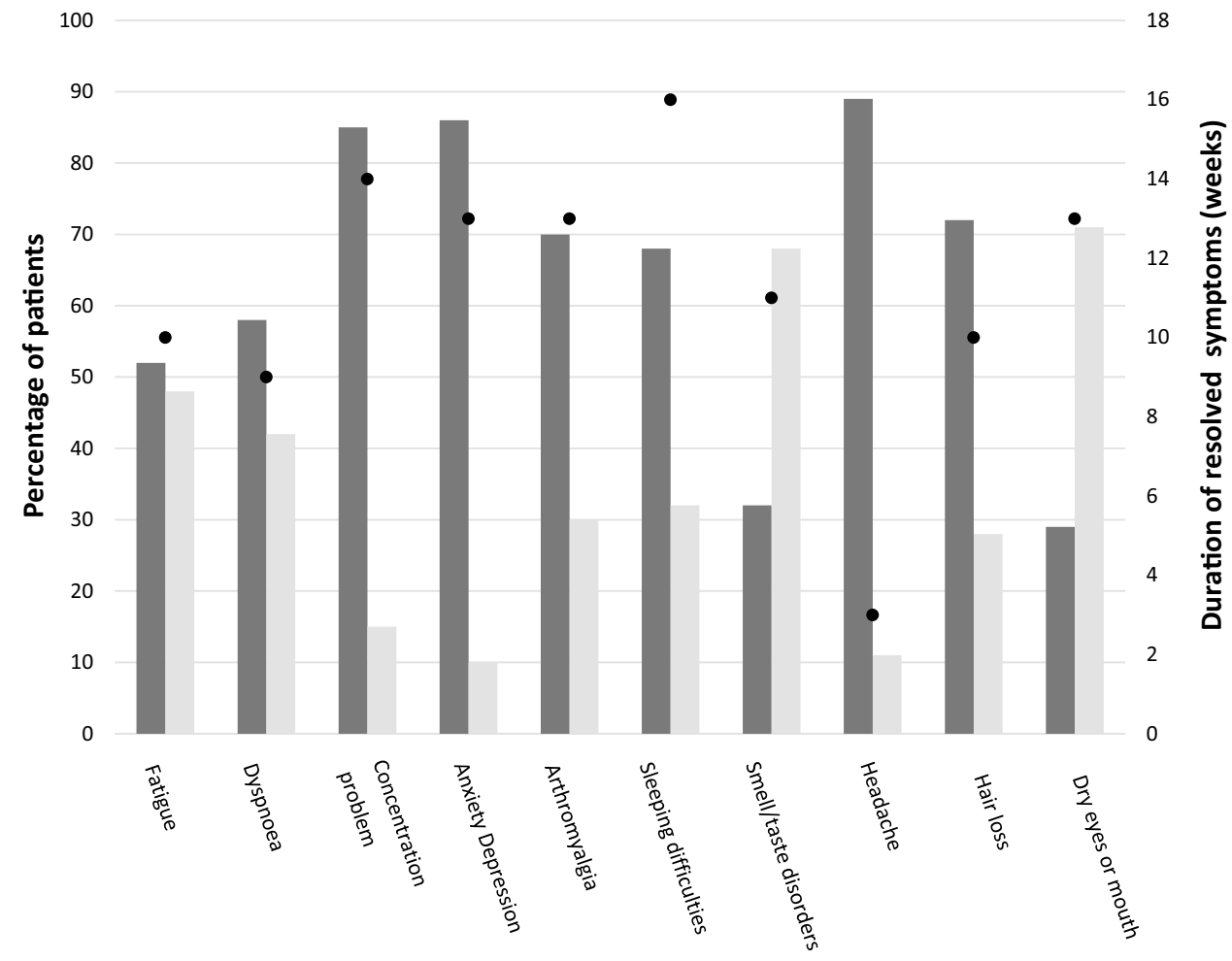

\begin{tabular}{l|l} 
Unresolved symptoms & Resolved symptoms
\end{tabular}

Mean duration of resolved symptoms

Table 2 Evaluation of possible risk factors associated with the most prevalent symptoms

\begin{tabular}{|c|c|c|c|c|c|c|c|c|c|c|}
\hline & \multicolumn{2}{|l|}{ Fatigue } & \multicolumn{2}{|l|}{ Dyspnoea } & \multicolumn{2}{|c|}{$\begin{array}{l}\text { Anxiety or Depres- } \\
\text { sion }\end{array}$} & \multicolumn{2}{|c|}{ Muscle or Join Pain } & \multicolumn{2}{|c|}{$\begin{array}{l}\text { Concentration prob- } \\
\text { lems }\end{array}$} \\
\hline & OR $(95 \% \mathrm{CI})$ & $p$ value & OR $(95 \% \mathrm{CI})$ & $p$ value & OR $(95 \% \mathrm{CI})$ & $p$ value & OR $(95 \% \mathrm{CI})$ & $p$ value & OR $(95 \% \mathrm{CI})$ & $p$ value \\
\hline $\begin{array}{l}\text { Gender } \\
\text { Men (ref) } \\
\text { Women }\end{array}$ & $\begin{array}{l}4.65 \\
(1.25-17.30)\end{array}$ & 0.02 & $\begin{array}{l}6.01 \\
(1.61-22.34)\end{array}$ & $<0.01$ & $\begin{array}{l}2.40 \\
(0.70-8.20)\end{array}$ & 0.16 & $\begin{array}{l}1.92 \\
(0.60-6.20)\end{array}$ & 0.30 & $\begin{array}{l}0.90 \\
(0.30-2.30)\end{array}$ & 0.87 \\
\hline Age & $\begin{array}{l}0.98 \\
(0.94-1.02)\end{array}$ & 0.31 & $\begin{array}{l}0.97 \\
(0.93-1.01)\end{array}$ & 0.20 & $\begin{array}{l}0.97 \\
(0.93-1.00)\end{array}$ & 0.12 & $\begin{array}{l}0.96 \\
(0.92-0.99)\end{array}$ & 0.03 & $\begin{array}{l}0.95 \\
(0.91-0.99)\end{array}$ & 0.04 \\
\hline $\begin{array}{l}\text { Comorbidities } \\
\text { None or } 1 \text { (ref) } \\
2 \text { or more }\end{array}$ & $\begin{array}{l}1.60 \\
(0.50-5.10)\end{array}$ & 0.42 & $\begin{array}{l}2.78 \\
(0.81-9.45)\end{array}$ & 0.10 & $\begin{array}{l}3.64 \\
(1.10-12.20)\end{array}$ & 0.04 & $\begin{array}{l}1.40 \\
(0.44-4.51)\end{array}$ & 0.57 & $\begin{array}{l}2.30 \\
(0.65-9.12)\end{array}$ & 0.09 \\
\hline $\begin{array}{l}\text { Need for HFO or MV } \\
\text { No (ref) } \\
\text { Yes }\end{array}$ & $\begin{array}{l}2.40 \\
(0.75-7.73)\end{array}$ & 0.14 & $\begin{array}{l}3.36 \\
(1.02-11.14)\end{array}$ & 0.05 & $\begin{array}{l}0.75 \\
(0.25-2.30)\end{array}$ & 0.61 & $\begin{array}{l}0.98 \\
(0.31-3.02)\end{array}$ & 0.97 & $\begin{array}{l}0.72 \\
(0.23-2.20)\end{array}$ & 0.56 \\
\hline
\end{tabular}

Most prevalent symptoms were considered those that occupied the first places when order by frequency

A regression logistic model was used for calculation of OR 95\% CI. MV (mechanical ventilation, including non-invasive and invasive mechanical ventilation); HFO (high-flow oxygen)

could reduce their anxiety, and will allow to allocate the available resources more efficiently.

Supplementary Information The online version contains supplementary material available at https://doi.org/10.1007/s11739-021-02895-6.
Author contributions Conceptualization, writing, and original draft: CT and JF; methodology and formal analysis: CT, JC A-B; investigation: CT, SA, A,M and AN; writing, review, and editing: CT and JC A-B. 
Funding No funding was provided for this study.

Availability of data and materials The datasets used and/or analysed during the current study are available from the corresponding author on reasonable request.

Code availability Not applicable.

\section{Declarations}

Conflict of interest The authors declare that there is no conflict of interests.

Ethics approval The study was approved by the Arnau de VilanovaLlíria Hospitals' Ethics Committee.

Informed consent Patients provided informed verbal consent during the telephone interview.

Consent for publication Data are anonymous and managed as aggregated data.

\section{References}

1. O'Sullivan O (2021) Long-term sequelae following previous coronavirus epidemics. Clin Med (Lond) 21(1):e68-e70. https:// doi.org/10.7861/clinmed.2020-0204

2. Ahmed H, Patel K, Greenwood DC, Halpin S, Lewthwaite P, Salawu A, Eyre L, Breen A, O'Connor R, Jones A, Sivan M (2020) Long-term clinical outcomes in survivors of severe acute respiratory syndrome and Middle East respiratory syndrome coronavirus outbreaks after hospitalisation or ICU admission: A systematic review and meta-analysis. J Rehabil Med. https://doi. org/10.2340/16501977-2694

3. Carfî A, Bernabei R, Landi F, Gemelli Against COVID-19 PostAcute Care Study Group (2020) Persistent symptoms in patients after acute COVID-19. JAMA 324:603-605. https://doi.org/10. 1001/jama.2020.12603

4. Huang C, Huang L, Wang Y, Li X, Ren L, Gu X, Kang L, Guo L, Liu M, Zhou X, Luo J, Huang Z, Tu S, Zhao Y, Chen L, Xu D, Li Y, Li C, Peng L, Li Y, Xie W, Cui D, Shang L, Fan G, Xu J, Wang G, Wang Y, Zhong J, Wang C, Wang J, Zhang D, Cao B (2021) 6-month consequences of COVID-19 in patients discharged from hospital: a cohort study. Lancet 397(10270):220-232. https://doi. org/10.1016/s0140-6736(20)32656-8

5. Klein H, Asseo K, Karni N, Benjamini Y, Nir-Paz R, Muszkat M, Israel S, Niv MY (2021) Onset, duration and unresolved symptoms, including smell and taste changes, in mild COVID-19 infection: a cohort study in Israeli patients. Clin Microbiol Infect 27(5):769-774. https://doi.org/10.1016/j.cmi.2021.02.008
6. Halpin SJ, McIvor C, Whyatt G, Adams A, Harvey O, McLean L, Walshaw C, Kemp S, Corrado J, Singh R, Collins T, O'Connor RJ, Sivan M (2021) Postdischarge symptoms and rehabilitation needs in survivors of COVID-19 infection: a cross-sectional evaluation. J Med Virol 93(2):1013-1022. https://doi.org/10.1002/jmv.26368

7. Moreno-Pérez O, Merino E, Leon-Ramirez JM, Andres M, Ramos JM, Arenas-Jiménez J, Asensio S, Sanchez R, Ruiz-Torregrosa P, Galan I, Scholz A, Amo A, González-delaleja P, Boix V, Gil J, COVID 19-ALC Research Group (2021) Post-acute COVID19 syndrome. Incidence and risk factors: a Mediterranean cohort study. J Infect 82(3):378-383. https://doi.org/10.1016/j.jinf.2021. 01.004

8. Liang L, Yang B, Jiang N, Fu W, He X, Zhou Y, Ma WL, Wang X (2020) Three-month follow-up study of survivors of coronavirus disease 2019 after discharge. J Korean Med Sci. https://doi.org/ 10.3346/jkms.2020.35.e418

9. Tortajada C, Colomer E, Andreu-Ballester JC, Esparcia A, Oltra C, Flores J (2021) Corticosteroids for COVID-19 patients requiring oxygen support? Yes, but not for everyone: effect of corticosteroids on mortality and intensive care unit admission in patients with COVID-19 according to patients' oxygen requirements. J Med Virol 93(3):1817-1823. https://doi.org/10.1002/jmv.26635

10. Goldberg D, Bridges K, Duncan-Jones P, Grayson D (1988) Detecting anxiety and depression in general medical settings. $\mathrm{Br}$ Med J 297:897. https://doi:10.1136/bmj.297.6653.897

11. Mahler DA, Wells CK (1988) Evaluation of clinical methods for rating dyspnea. Chest 93(3):580-586. https://doi.org/10.1378/ chest.93.3.580

12. EuroQol Research Foundation. EQ-5D-5L User Guide (2019) Available from: https://euroqol.org/publications/user-guides

13. Tenforde MW, Kim SS, Lindsell CJ, Billig Rose E, Shapiro NI, Files DC, Gibbs KW, Erickson HL, Steingrub JS, Smithline HA, Gong MN, Aboodi MS, Exline MC, Henning DJ, Wilson JG, Khan A, Qadir N, Brown SM, Peltan ID, Rice TW, Hager DN, Ginde AA, Stubblefield WB, Patel MM, Self WH, Feldstein LR, IVY Network Investigators; CDC COVID-19 Response Team; IVY Network Investigators (2020) Symptom duration and risk factors for delayed return to usual health among outpatients with covid-19 in a multistate health care systems network-United States, March-June 2020. Morb Mortal Wkly Rep 69:993-998. https://doi.org/10.15585/mmwr.mm6930e1

14. Havervall S, Rosell A, Phillipson M, Mangsbo SM, Nilsson P, Hober S, Thålin C (2021) Symptoms and functional impairment assessed 8 months after mild covid-19 among health care workers. JAMA 325(19):2015-2016. https://doi.org/10.1001/jama.2021. 5612

15. Xiong Q, Xu M, Li J, Liu Y, Zhang J, Xu Y, Dong W (2021) Clinical sequelae of COVID-19 survivors in Wuhan, China: a single-centre longitudinal study. Clin Microbiol Infect 27(1):89-95. https://doi.org/10.1016/j.cmi.2020.09.023

Publisher's Note Springer Nature remains neutral with regard to jurisdictional claims in published maps and institutional affiliations. 